\title{
PROGRESS IN UNDERSTANDING OF ALKALI METAL INTERACTION WITH A SILICON SURFACE
}

\author{
P. SOUKIASSIAN*
}

Commissariat à l'Energie Atomique, Service de Recherche sur les Surfaces et l'Irradiation de la Matière, Centre d'Etudes de Saclay 91191 Gif sur Yvette Cedex, France and

Département de Physique, Université de Paris-Sud, 91405 Orsay Cedex, France

(Received June 12, 1991)

The atomic and electronic structure and interface formation of alkali metal $(\mathrm{Na}, \mathrm{K}, \mathrm{Rb}, \mathrm{Cs})$ and $\mathrm{Si}(100) 2 \times 1$ surfaces is investigated by photoemission - XPS, UPS - using synchrotron radiation, scanning tunneling microscopy (STM) and by photoemission extended X-ray absorption fine structure (PEXAFS) experiments. The XPS-UPS results indicate that the alkali metal-silicon bond is a weak and polarized covalent bonding even at low coverages with adsorbate metallization at the monolayer. In contrast to III-V semiconductor surfaces, alkali metals do not induce significant structural changes of the surface: STM images performed with atomic resolution for the representative $\mathrm{K} / \mathrm{Si}(100) 2 \times 1$ systems demonstrate that, at one monolayer coverage, the $\mathrm{K}$ atoms form one-dimensional linear metallic chains parallel to the Si dimers rows $\langle 110\rangle$ direction and distant by $7.68 \AA$ with a single site of adsorption. Below half a monolayer, the $\mathrm{K}$ atoms occupy various coexisting sites with no long range order. An ordering transition occurs around half a monolayer in which the adsorbate-adsorbate interaction, which was so far neglected in theoretical calculations, appears to be the leading driving force. The proposed models and concepts are discussed and compared to the latest state-of-art theoretical calculations.

PACS numbers: 68.35.-p, 73.20.At, 79.60.Eq, 82.65.My USA.

*Also at Department of Physics, Northern Illinois University, DeKalb, Illinois 60115-2854, 


\section{Introduction}

Surface science was basically initiated at the beginning of the 20th century by the investigations of Langmuir, Taylor, Gurney and Topping on the effect of alkali metals on the electronic emission of tungsten cathods [1-3]. Since that time, alkali metal adsorption on metallic or semiconducting surfaces was intensively investigated because of fundamental as well as many applied aspects such as catalysis, negative electron affinity cathodes, ion propulsion, photoelectric or thermionic emitters, thermionic conversion, Schottky barrier formation, negative ion sources for neutral beam devices [4-8]. Another striking aspect of alkali metals is their exceptional and versatile role in the promoted oxidation and/or the nitridation of semiconductor surfaces $[9,10]$. Langmuir and Taylor have shown that Cs vapors induced a dramatic increase in the electronic emission of tungsten cathods as a result of the very important decrease (several volts) of the substrate work function. The model proposed by Langmuir, Taylor, Gurney and Topping at about the same time suggested that the alkali metal transfers its valence electron to the surface leading to the formation of an ionic bonding. The $\mathrm{Cs}^{+}$ion forms with its image a dipole leading to the reduction of the surface work function [1-3]. When the $\mathrm{Cs}^{+}-\mathrm{Cs}^{+}$distance is reduced with increasing coverages, the $\mathrm{Cs}^{+}-\mathrm{Cs}^{+}$interaction provokes depolarization of the dipoles and subsequent minimum in the substrate work function around half a monolayer. Beyond, the Cs overlayer becomes metallic [1-3]. Until the early 80 's, this picture was believed to be valid for all types of surfaces because the shape and the decrease of the work function upon alkali metal deposition was very similar for a large variety of substrates [11, 12]. However, even in its more recent approaches, the ionic bonding model was unable to explain the electronic properties of alkali metal adsorption on transition metal surfaces [13, 14]. In this case, it is necessary to have theoretical methods taking into account the true electronic structure of the surface in particular the presence of highly localized electronic surface states [15]. From theoretical FLAPW ab initio calculations using the local density functional approach (LDF) $[15,16]$ as well as from photoemission experiments using synchrotron radiation (XPS, UPS) and electron energy loss spectroscopies (ELS) [13, 14, 17], it was demonstrated that the nature of the bonding between alkali metal adsorbates and transition metal surfaces such as $\mathrm{W}(100), \mathrm{Mo}(100), \mathrm{Ta}(100), \mathrm{Mo}(110)$ and $\mathrm{W}(110)$ was strong, polarized and covalent even at low coverages [17]. This bonding was shown to be formed as a result of the hybridization between the alkali $s$ valence electron and the substrate localized electronic $d$ surface state $[15,17]$. The absence of significant charge transfer was also demonstrated by the lack of large shifts at the substrate and/or adsorbate core levels $[17,18]$. In contrast, the classic ionic bonding picture appears to remain suitable for jellium-like surfaces like aluminium or full $d$-band metal as reported on the footing of surface extended X-ray absorption fine structures (SEXAFS), UPS and ELS measurements [19-21]. The case of the electronic properties of alkali metal/semiconductor systems is interesting since these surfaces and interfaces have also, like transition metals [22], localized electronic surface states as dangling bonds. So, one of the important issues is to know if one of these pictures could also be valid for elemental semiconductor/alkali metal systems. 
In this article, I will review the current status about the atomic and electronic structures of alkali metal/silicon systems based on our recent investigations with photoemission (XPS-UPS) using synchrotron radiation, extended X-ray absorption fine structures (SEXAFS-PEXAFS) and scanning tunneling microscopy (STM) experiments. The proposed models and concepts of alkali metal adsorption on silicon will be discussed and compared with the most recent theoretical calculations.

\section{Experimental details}

The XPS-UPS and PEXAFS experiments were performed at the Synchrotron Radiation Center of the University of Wisconsin-Madison using an experimental chamber at pressure better than $3 \cdot 10^{-11}$ torr. The photoelectron energy was analyzed by an angle-integrating double pass cylindrical mirror analyzer (CMA). Alkali metal deposition was performed using SAES Getters sources. Since surfaces modified by alkali metal overlayers have been shown to be highly sensitive to impurities [9], a special care was taken to keep the surface clean. The pressure increase during alkali metal deposition always remains below $2 \cdot 10^{-11}$ torr. More details about experiments and data analysis could be found elsewhere $[6,9,10]$.

\section{Electronic properties of alkali metal/Si(100)2 11 surfaces:} nature of the bonding, bond length and surface metallization

One way to trace if the bonding between an adsorbate and a substrate is ionic is to look at the effect of high and low electronegative species on the surface of interest, here silicon. Adsorption of a highly electronegative element such as fluorine on $\operatorname{Si}(100) 2 \times 1, \operatorname{Si}(111) 2 \times 1$ and $\operatorname{Si}(111) 7 \times 7$ surfaces has been shown to induce very large chemical shifts (several electron volts) to higher binding energies at the Si $2 p$ core level observed in photoemission spectroscopy as a result of an important charge transfer from the silicon surfaces to the adsorbate [23]. On the other side, deposition of low electron affinity elements such as calcium on silicon surfaces has been shown to induce an important chemical shift $(1 \mathrm{eV})$ to lower binding energy at the Si $2 p$ core level as a result of a charge transfer from the adsorbate to the substrate [24]. So, in case of a strong ionic bonding between alkali metals and silicon surfaces as favored by recent pseudopotential calculations [25], one should at least expect dramatic changes into the Si $2 p$ core level, with existence of a large chemical shift to lower binding energy. Instead, there is no significant change of the Si $2 p$ core level line observed in photoemission for $\mathrm{Na}, \mathrm{K}, \mathrm{Rb}$ and Cs deposition on the (100) surface of silicon as shown in Fig. 1 [6]. This rules out the model of an ionic bonding claimed [25] on the footing of pseudopotential calculations.

Figure 2 displays valence band photoemission spectra for the representative $\mathrm{Na} / \mathrm{Si}(100) 2 \times 1$ interface at various sodium coverages. On the clean surface, peak A represents the $3 p$ electronic surface state related to the dangling bond while peak $\mathrm{B}$ is connected with a bulk-like state. In case of a strong ionic bonding, one should expect destruction of this electronic surface state (peak A) with $\mathrm{Na}$ 

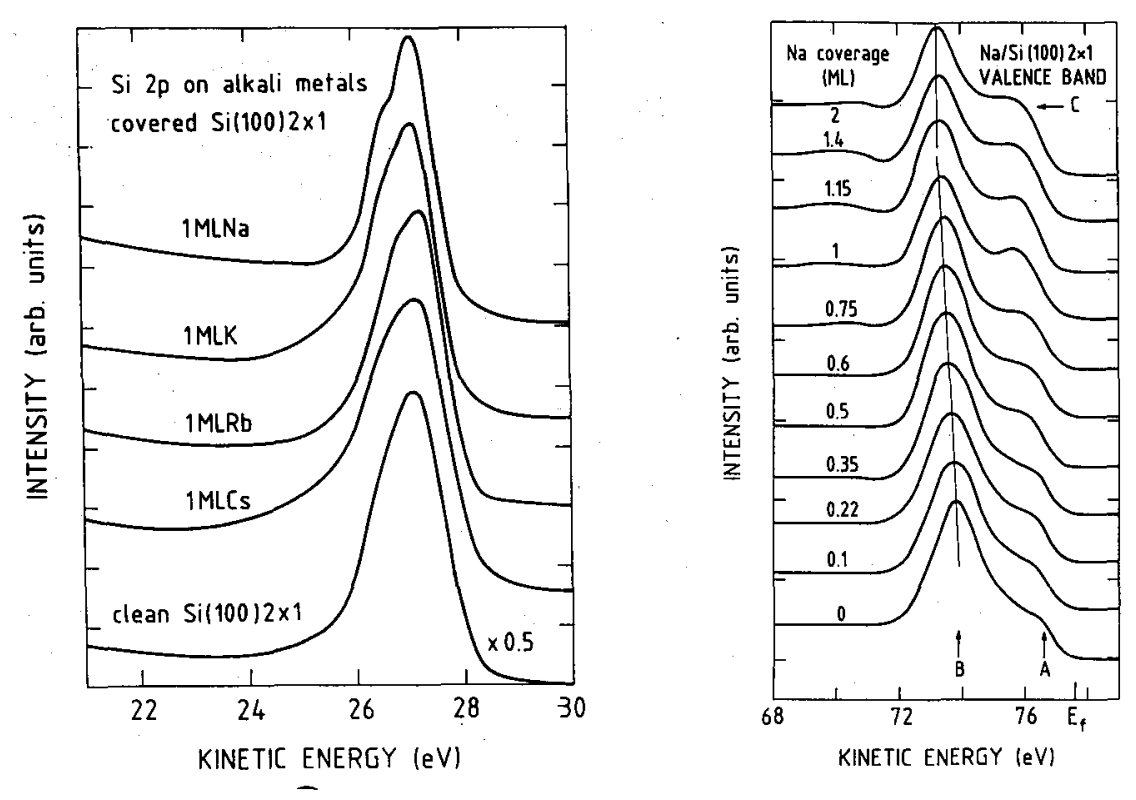

Fig. 1. Si $2 p$ core level for a $\operatorname{Si}(100) 2 \times 1$ surface covered with 1 monolayer (1 ML) of $\mathrm{Cs}, \mathrm{Rb}, \mathrm{K}$ and $\mathrm{Na}$. The photon energy was $130 \mathrm{eV}$.

Fig. 2. $\mathrm{Na} / \mathrm{Si}(100) 2 \times 1$ : valence band spectra for various sodium coverages between 0 and 2 monolayers. The photon energy was $82 \mathrm{eV}$.

deposition. Instead, upon $\mathrm{Na}$ adsorption, peak $\mathrm{A}$ has its intensity increased with the coverage up to one monolayer ( $1 \mathrm{ML}$ ). Then, from 1 to $2 \mathrm{ML}$, the intensity of peak A decreases. This behavior indicates formation of an electronic interface state (peak C) at $1 \mathrm{Na} \mathrm{ML}$ with a $1.8 \mathrm{eV}$ binding energy [26]. Similar electronic interface states have been shown to occur with other alkali metals on silicon [26, 27] as well as germanium surfaces [28]. In all cases, the formation of these electronic interface states is related to the hybridization $[26,29]$ between the alkali $s$ valence orbitals with the substrate $p$ dangling bond leading to a covalent bonding [26, $30]$. The alkali $s$ valence electron, which has an extended wave function, loses part of its $s$ character through the hybridization with the more localized $p$ dangling bond $[6,26]$.

Another aspect of alkali metal/silicon surfaces could be obtained by looking at the $\mathrm{Na} 2 p$ core levels for the representative $\mathrm{Na} / \mathrm{Si}(100) 2 \times 1$ system in Figs. $3 \mathrm{a}$ and $3 \mathrm{~b}$. As can be seen from Fig. $3 \mathrm{a}$, the $\mathrm{Na} 2 p$ core level exhibits a feature around $2.5 \mathrm{eV}$ lower kinetic energy at coverages above half a $\mathrm{Na}$ monolayer. This is related to the formation of plasma oscillations $[6,26]$. Further confirmation of this aspect could be found by exposing the system to small amount of oxygen as shown in Fig. 3b where the plasmon frequency is reduced as a result of charge transfer from $\mathrm{Na}$ to oxygen leading to the reduction of electrons involved in 

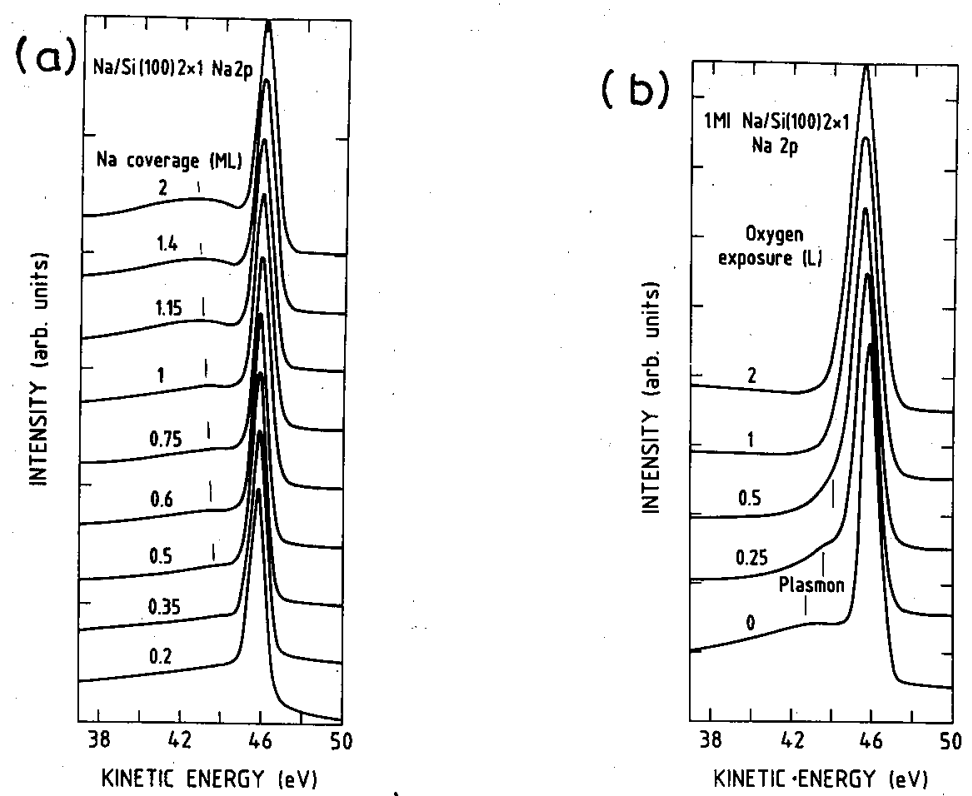

Fig. 3. (a) $1 \mathrm{ML} \mathrm{Na} / \mathrm{Si}(100) 2 \times 1: \mathrm{Na} 2 p$ core level spectra at various sodium coverages. The photon energy was $82 \mathrm{eV}$. (b) $\mathrm{O}_{2} / 1 \mathrm{ML} \mathrm{Na} / \mathrm{Si}(100) 2 \times 1: \mathrm{Na} 2 p$ core level spectra at various oxygen exposures. The photon energy was $82 \mathrm{eV}$.

collective oscillations and plasmon destruction at 1 Langmuir (1 Langmuir $=1 \mathrm{~L}$ $=10^{-6}$ torr $\cdot \mathrm{s}$ ) of oxygen exposure $[6,26]$. Similar findings have been made for silicon surfaces covered with $\mathrm{Cs}$ or $\mathrm{K}[6,31,32]$ and Ge surfaces covered with $\mathrm{Na}$ [28]. The existence of plasmons within the alkali overlayer demonstrates adsorbate metallization (and not substrate metallization as claimed in pseudopotential calculations [25]) in agreement with previous theoretical investigations [33].

Another interesting feature is the rather low temperatures of desorption of alkali metals from silicon surfaces which have been shown to be necessary to remove the adsorbate from the silicon $(100)$ surface, between $550^{\circ} \mathrm{C}$ and $650^{\circ} \mathrm{C}$ for $\mathrm{Na}, \mathrm{K}, \mathrm{Rb}$ and $\mathrm{Cs}$, respectively [34-37]. This indicates that the bonding between the alkali metal adsorbate and the silicon substrate is weak [34,35] especially if a comparison is made with transition metal surfaces (on which the alkali metal is strongly bonded to the surface $[15,17])$ where temperatures well above $1000^{\circ} \mathrm{C}$ are necessary to desorb the alkali overlayer [38].

Further insights about the nature of the alkali metal-silicon bonding are provided by using EXAFS techniques to measure the bond length between the adsorbate and the substrate. SEXAFS measurements for the K/Si(100) $2 \times 1$ system at $1 \mathrm{~K} \mathrm{ML}$ give a $\mathrm{K}-\mathrm{Si}$ bond length of $3.14 \pm 0.01 \AA$ (Table) which corresponds exactly to the sum of $\mathrm{K}$ and Si covalent radii [39]. PEXAFS investigations using 
TABLE

Interatomic distances measured* by SEXAFS and PEXAFS.

SEXAFS (from Ref. [39])

\begin{tabular}{c|c|c}
\hline \hline System & Auger line & $R 1(\AA)$ \\
\hline $1 \mathrm{ML} \mathrm{K} / \mathrm{Si}(100) 2 \times 1$ & $\mathrm{~K} K L L$ & $3.14 \pm 0.10$ \\
\hline
\end{tabular}

PEXAFS (from Ref. [4])

\begin{tabular}{l|l|c|c|c}
\hline \multicolumn{1}{c|}{ System } & Photopeak & $R 1(\AA)$ & $r 2(\AA)$ & $R 3(\AA)$ \\
\hline Clean Si(100)2 21 & $\mathrm{Si} 2 p$ & $2.34 \pm 0.04$ & $3.87 \pm 0.08$ & $4.69 \pm 0.10$ \\
$0.4 \mathrm{ML} \mathrm{Na} / \mathrm{Si}(100) 2 \times 1$ & $\mathrm{Si} 2 p$ & $2.35 \pm 0.05$ & $3.86 \pm 0.08$ & $4.72 \pm 0.10$ \\
$1 \mathrm{ML} \mathrm{Na} / \mathrm{Si}(100) 2 \times 1$ & $\mathrm{Si} 2 p$ & $2.32 \pm 0.06$ & $3.85 \pm 0.08$ & $4.75 \pm 0.13$ \\
$0.3 \mathrm{LO}_{2} / 1 \mathrm{ML} \mathrm{Na} / \mathrm{Si}(100) 2 \times 1$ & $\mathrm{Si} 2 p$ & $2.50 \pm 0.08$ & $3.92 \pm 0.08$ & $4.91 \pm 0.10$ \\
$1 \mathrm{ML} \mathrm{Cs} / \mathrm{Si}(100) 2 \times 1$ & $\mathrm{Si} 2 p$ & $2.36 \pm 0.06$ & $3.90 \pm 0.08$ & $4.78 \pm 0.13$ \\
$0.4 \mathrm{ML} \mathrm{Na} / \mathrm{Si}(100) 2 \times 1$ & $\mathrm{Na} 2 p$ & $2.80 \pm 0.10$ & $4.40 \pm 0.12$ & \\
$1 \mathrm{ML} \mathrm{Na} / \mathrm{Si}(100) 2 \times 1$ & $\mathrm{Na} 2 p$ & $2.78 \pm 0.10$ & $4.36 \pm 0.12$ & \\
\hline
\end{tabular}

*All measurements were made at $\theta=25^{\circ}$, where $\theta$ is the angle between the surface normal and the electric vector of incoming synchrotron radiation. These values are obtained from the $F(R)$ after phase shift correction. $R 1, R 2$ and $R 3$ indicate the first, second and third nearest neighbors.

the $\mathrm{Na} 2 p$ core level in the constant initial state mode (CIS) for the $\mathrm{Na} / \mathrm{Si}(100) 2 \times 1$ interface indicate that the $\mathrm{Na}-\mathrm{Si}$ bond length is the same for $0.4 \mathrm{Na} \mathrm{ML}$ and $1 \mathrm{Na}$ ML at $2.80 \pm 0.01 \AA$ which corresponds closely to the sum of $\mathrm{Na}$ and $\mathrm{Si}$ covalent radii [40] (see Table and Fig. 4 which displays the Fourier transform $F(R)$ without phase shift correction of the EXAFS signal). These results support the model of covalent bonding described above. It is interesting to remark that they are in a very good agreement with recent total energy ab initio calculations for the $\mathrm{K} / \mathrm{Si}(100) 2 \times 1[41,42]$ and $\mathrm{Na} / \mathrm{Si}(100) 2 \times 1$ systems [43] as well as latest dynamical low energy electron diffraction (LEED) investigations [44]. Also of interest is the absence of a bond length change between 0.4 and $1 \mathrm{Na} \mathrm{ML}$ - see Table and [40] as observed for a metal substrate like $\mathrm{Ag}$ [19]. In this case, the increase of the $\mathrm{Cs}-\mathrm{Ag}$ bond length by $0.3 \AA$ between $0.5 \mathrm{Cs} \mathrm{ML}$ and $1 \mathrm{Cs} \mathrm{ML}$ was interpreted as a result of a transition from an ionic to a covalent state [19], in agreement with the classic ionic bonding picture [1-3]. This suggests that, in the case of alkali metal/silicon interfaces, the bonding remains the same at low and monolayer coverages, e.g. covalent which is in agreement with the observed electronic properties since:

i) hybridization between alkali metal and silicon valence electrons already occurs at low coverages $[26,28]$ and ii) there is no significant core level shift indicating that a charge transfer occurs at low alkali metal coverages $[6,45]$.

The decrease of the substrate work function with alkali metal coverages $(-3$, $-3.2,-3.4 \mathrm{eV}$ for $\mathrm{Na}, \mathrm{K}$ and $\mathrm{Cs}$ respectively $[10,46-49]$ ) also indicates that the covalent bonding between the alkali and the silicon atoms is polarized similar to the case mentioned above of Cs covered transition metal surfaces [15]. Also of 


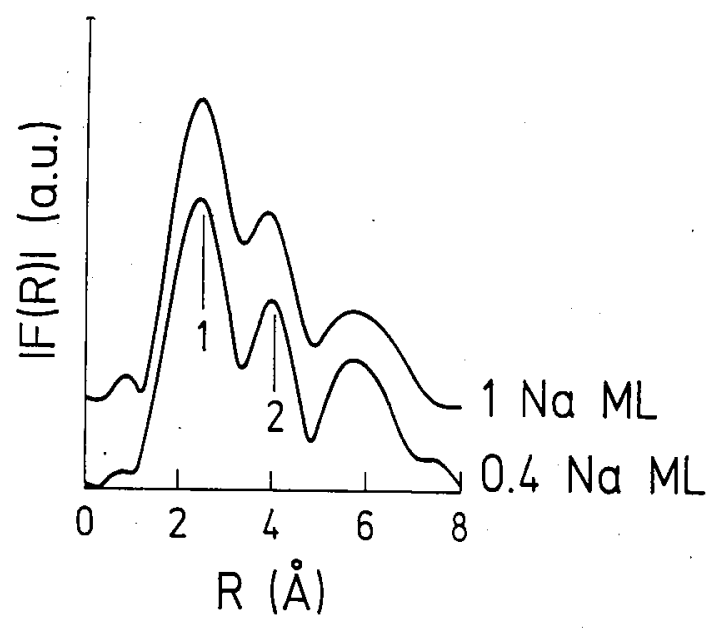

Fig. 4. Magnitude of the Fourier transform $F(R)$ measured from PEXAFS oscillations at the $\mathrm{Na} 2 p$ core level for clean $\mathrm{Si}(100) 2 \times 1,0.4 \mathrm{ML} \mathrm{Na} / \mathrm{Si}(100) 2 \times 1$ and $1 \mathrm{ML}$ $\mathrm{Na} / \mathrm{Si}(100) 2 \times 1$ systems.

interest, the absence of significant core level shift at the Si $2 p$ core level mentioned above indicates that alkali metals (except lithium) do not interdiffuse through the surface with no silicide formation in contrast to the behavior observed for many other metals [5].

This model of weak and polarized covalent bonding [26] is now further supported by several other recent investigations using metastable deexcitation spectroscopy (MDS) [51] and high resolution core level photoemission experiments using synchrotron radiation [45] on alkali metal covered silicon surfaces.

\section{Structural properties of alkali metal/Si(100) $2 \times 1$ system}

\subsection{Potassium atoms ordering on the $\operatorname{Si}(100) 2 \times 1$ surface investigated by STM}

During many years, the structural properties of alkali metal adsorption were investigated using rather conventional electron diffraction techniques at low or high energies (LEED, RHEED) [48, 52-56]. The first model was proposed nearly 20 years ago by Levine using LEED measurements for the Cs/Si(100) $2 \times 1$ system in which Cs was shown to keep the same $2 \times 1$ reconstruction at all coverages [52]. Levine suggested that Cs atoms are adsorbed in one-dimensional chains parallel to the silicon dimer row along the $\langle 110\rangle$ direction with a single site of adsorption being the pedestal site (see Fig. 5). Later, Tochihara studied the K/Si(100) $2 \times 1$ surface and came to the conclusion that the picture described by Levine for Cs was also valid for potassium [53]. It is only recently that these systems were revisited with the use of more sophisticated techniques. Abukawa and Kono using photoelectron diffraction (PED) measurements with a single scattering analysis 


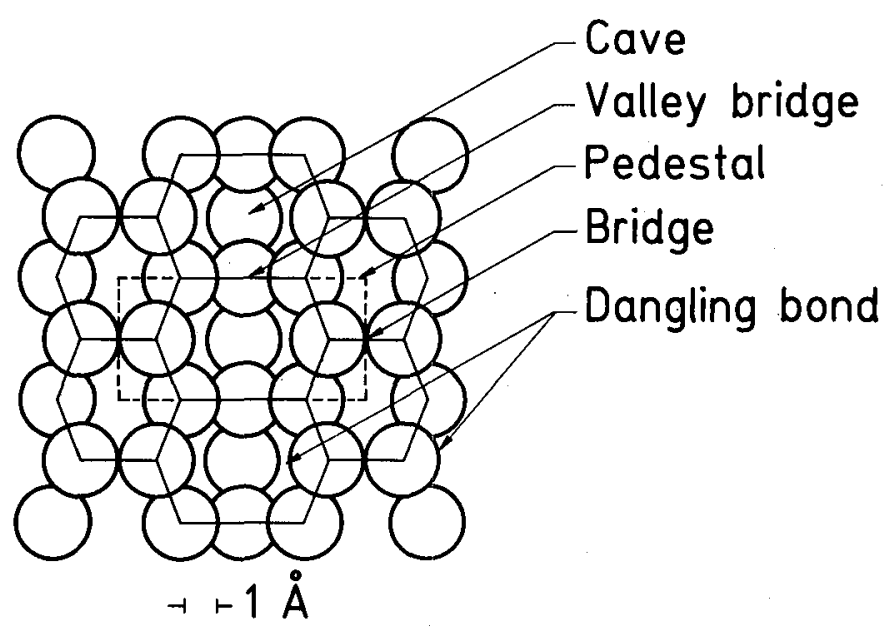

$\mathrm{Si}$

Fig. 5. Model of the reconstructed $\mathrm{Si}(100)$ surface with all the possible sites of alkali metal adsorption suggested in the literature.

suggested that Cs $(K)$ are adsorbed on both pedestal and valley bridge sites in a two-layer model [57]. Similar suggestions of a two-layers model were also made using other experimental techniques such as thermal desorption experiments (TDS) [58], RHEED [59], dynamical LEED [56] and medium energy ion scattering (MEIS) [60] while ELS measurements [32] support the one-dimensional chain model proposed by Levine [52]. Total energy $a b$ initio D-MOL calculations for the representative $\mathrm{K} / \mathrm{Si}(100) 2 \times 1$ system have shown that the energy for each proposed site of adsorption is very close and that the most favorable site would be the cave site (see Fig. 5) [41, 42].

In order to be able to solve some of these controversies, scanning tunneling microscopy (STM) experiments for the $\mathrm{K} / \mathrm{Si}(100) 2 \times 1$ system were performed on a stepped $\left(4^{\circ}\right)$ surface [61]. In this case, each terrace has the same $2 \times 1$ domain and is large enough to represent a normal (100) $2 \times 1$ surface. Furthermore, the $\langle 110\rangle$ direction is perpendicular to the step edge which could allow to determine the orientation of alkali chains. Figure 6 a displays the STM image for the $1 \mathrm{~K}$ $\mathrm{ML} / \mathrm{Si}(100) 2 \times 1$ interface by tunneling into the filled states. The $\mathrm{K}$ atoms appear to be adsorbed along one-dimensional linear chains parallel to the $\mathrm{Si}(100) 2 \times 1$ dimer rows (the $\langle 110\rangle$ direction) and distant by $7.68 \AA[61,62]$. The STM picture obtained by tunneling into the empty states gives a complementary image (Fig. $6 \mathrm{~b}$ and Ref. [61]). This picture is consistent with the model of Levine [52] but could as well be valid for cave adsorption sites as proposed by Ling Ye, Freeman and Delley on the basis of total energy $a b$ initio D-MOL calculations [41]. The corrugations measured by tunneling into filled and empty states are $1.5 \AA$ and $0.7 \AA$ respectively. Since the largest vertical distance between top and low $K$ heights in the two-layers 

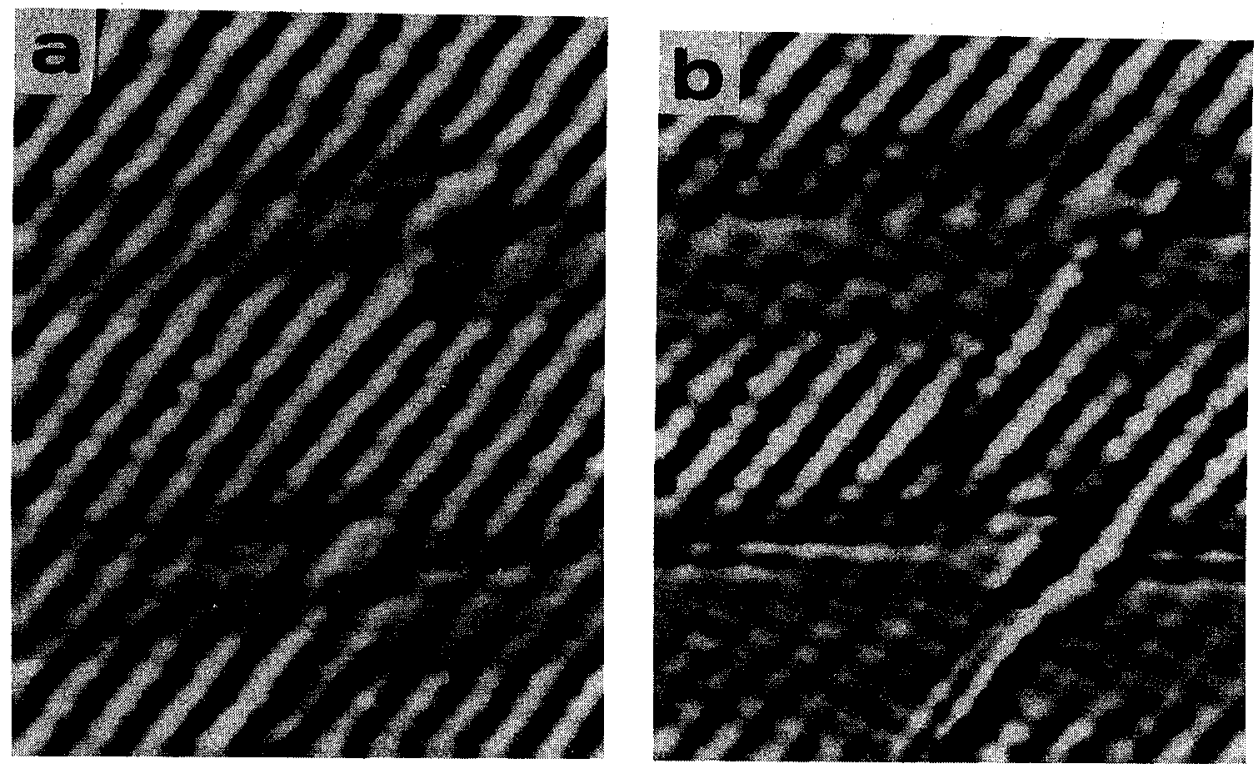

Fig. 6. (a) STM image (filled states) of $1 \mathrm{ML}$ of potassium on the $\operatorname{Si}(100) 2 \times 1-4^{\circ}$ -stepped surface $\left(V_{t}=+1.2 \mathrm{~V}\right)$. The distance between 2 potassium chains is $7.68 \AA$. (b) STM image (empty states) of $1 \mathrm{ML}$ of potassium on the $\operatorname{Si}(100) 2 \times 1-4^{\circ}-$ stepped surface $\left(V_{t}=-1.2 \mathrm{~V}\right)$.

models is $0.55 \AA$ (this distance is calculated using the measured $\mathrm{K}-\mathrm{Si}$ bond length at $3.14 \AA[39]$ ), this means that the presence of a second layer as favored by other techniques [56-60]. would have been clearly seen on the STM picture [61] and Fig. 6a. Therefore, the STM results [61] which, unlike other experimental technique [52,53,56-60], provide a more "direct view" of the $\mathrm{K}$ atoms on the $\mathrm{Si}(100) 2 \times 1$ surface, definitively favor a one-layer model with a single site of adsorption and do not support at all other suggestions of 2-layers or 2-sites models [56-60]. It is interesting to remark in Fig. 6a that the $\mathrm{K}$ one-dimensional chains pass over the step edges to be bonded to the corresponding chains of the next terrace without following the substrate registry at the step edge. This indicates that the $\mathrm{K}-\mathrm{K}$ interaction is stronger than the $\mathrm{K}-\mathrm{Si}$ interaction (which is weak as explained above). Furthermore, at low coverages, the STM images indicate that $\mathrm{K}$ is adsorbed on various coexisting sites with no long-range order [61]. This suggests the existence of an ordering transition around half a monolayer in which the adsorbate-adsorbate interaction appears to be the leading driving force [61]. Also of interest in Fig. 6a is the existence of 3D potassium clusters at the step edge which are likely to result from $\mathrm{K}$ adsorption on surface defects [61, 62]. It is also possible that this effect might result from enhanced sticking probabilities at the step edge as recently suggested for Cs adsorption on silicon surfaces [63]. However, in this case, a more important effect should, in principle, be observed. 
So interpretation of these 3D clusters in terms of surface defects is more plausible [61].

\subsection{Effect of $\mathrm{Na}$ or $\mathrm{Cs}$ on the structure of the Si(100) $2 \times 1$ surface}

The adsorption of alkali metals on surfaces, even at very low coverages has been shown to induce dramatic structural changes (reconstruction and/or removal of relaxation) of the surfaces of metals like $\mathrm{W}(100)$ or $\mathrm{Mo}(100)[17,64]$ or semiconductors like $\operatorname{InP}(110)$ [65]. So it is interesting to investigate if such structural changes also occur in the case of silicon surfaces. Figure 7 displays the Fourier

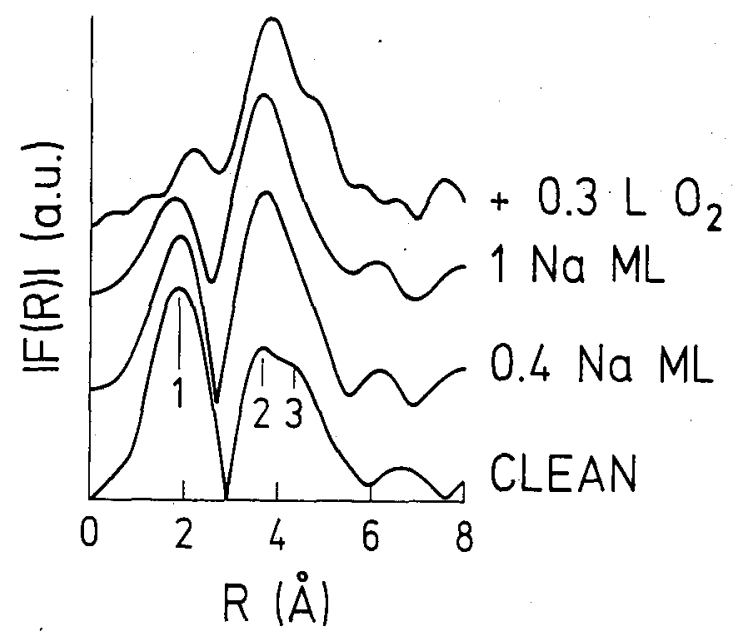

Fig. 7. Magnitude of the Fourier transform $F(R)$ measured from the PEXAFS oscillations at $\mathrm{Si} 2 p$ core level for clean $\mathrm{Si}(100) 2 \times 1,0.4 \mathrm{ML} \mathrm{Na} / \mathrm{Si}(100) 2 \times 1,1 \mathrm{ML}$ $\mathrm{Na} / \mathrm{Si}(100) 2 \times 1$ and $0.3 \mathrm{~L}$ of $\mathrm{O}_{2} / 1 \mathrm{ML} \mathrm{Na} / \mathrm{Si}(100) 2 \times 1$ systems.

transform (without phase shift correction) of the EXAFS signal at the Si $2 p$ core level from PEXAFS measurements for the $\mathrm{Na} / \mathrm{Si}(100) 2 \times 1$ [40]. As can be seen from Fig. 7, $\mathrm{Na}$ deposition on $\mathrm{Si}(100) 2 \times 1$ at $0.4 \mathrm{ML}$ and $1 \mathrm{ML}$ do not induce significant structural changes of the surface in the Si-Si first, second and third nearest neighbors [40]. The situation is similar for a larger alkali atom such as Cs - see Table. It is in contrast to the behavior observed for III-V compound semiconductors such as InP(110) where small $\mathrm{Na}$ coverages induce removal of the surface relaxation and surface reconstruction [65]. These differences may be related to the fact that, in the case of silicon surfaces, the $\mathrm{Na}(\mathrm{Cs})-\mathrm{Si}$ bond is weak as mentioned above. The absence of significant structural changes of the silicon (100) surface upon alkali metal deposition is consistent with recent dynamical LEED results in which it was found that $\mathrm{Na}$ induced $\mathrm{Si}-\mathrm{Si}$ dimer relaxation by $0.2 \AA$, which however is of the order of the accuracy of the measurement $( \pm 0.1 \AA)$ [55]. This relaxation is likely to result from charge redistribution through the formation of the $\mathrm{Na}-\mathrm{Si}$ 
covalent bonding [26]. Also of interest in Fig. 7 are the dramatic changes into the $\mathrm{Si}-\mathrm{Si}$ nearest neighbors induced by small oxygen exposures (below the threshold of catalytic oxidation [66]) which further stresses the very high sensitivity of surfaces modified by alkali metal overlayers [9].

\section{Conclusions}

In contrast to the historic ionic bonding picture of Langmuir, investigations by XPS-UPS photoemission using synchrotron radiation and surface EXAFS techniques of the adsorption of alkali metals on elemental semiconductors indicate the formation of a weak and polarized covalent bonding. This model, which is somewhat similar to the picture describing alkali metal/transition metal interfaces where a strong covalent bonding occurs, appears to be a rather general feature of surfaces having highly localized electronic states. It significantly differs from the historical ionic bonding picture popular for nearly 70 years which still seems to describe correctly the interaction of alkali metals with jellium-like or full $d$-band metal surfaces. STM images indicate that at $1 \mathrm{ML}, \mathrm{K}$ atoms form one-dimensional chains parallel to the Si dimers rows with the existence of an ordering transition around half a monolayer coverage in which the adsorbate-adsorbate interaction, which was so far neglected by theoreticians, appears to be the leading driving force. Finally, PEXAFS measurements also show that alkali overlayers do not significantly modify the surface structure of $\operatorname{Si}(100) 2 \times 1$.

\section{Acknowledgements}

This work was supported by the US National Science Foundation under contract $\mathrm{N}^{\circ}$ DMR 88-07754 through the Northern Illinois University, by the Commissariat à l'Energie Atomique - CEA, by the Dow Corning Corporation and by Xerox. The author is grateful to his collaborators and wants to especially acknowledge Tom Gentle, Zdenek Hurych, Tom Kendelewicz, Sung Kim, Joel Kubby and Hans Starnberg as well as close collaboration with Art Freeman, Shao-Ping Tang and Ling Ye. The expert and outstanding technical assistance of the staff of the Synchrotron Radiation Center at the University of Wisconsin-Madison is also acknowledged. The STM experiments were performed at the Xerox Webster Research Center. The author is grateful to the Xerox Webster Research Center for its hospitality.

\section{References}

[1] K.H. Taylor, I. Langmuir, Phys. Rev. 21, 380 (1923); I. Langmuir, J. Am. Chem. Soc. 54, 2788 (1932); Phys. Rev. 44, 224 (1933).

[2] J. Topping, Proc. Roy. Soc. A 114, 69 (1927).

[3] R.W. Gurney, Phys. Rev. 47, 479 (1935).

[4] N. Hatsopoulos, E.P. Gyftopoulos, in: Thermionic Energy Conversion, Cambridge, Massachusetts, MIT Press (1977); S.G. Forbes, in: Applied Physics in Engineering of Jet Rocket, Nuclear and Electric Propulsion: Theory and Design, Ed. W.H.T. Loh, Springer, New York, 7, 442 (1968). 
[5] H. Sonneberg, Appl. Phys. Lett. 19, 431 (1971); C.C. Wang, J. Appl. Phys. 49, 147 (1977); M.E. Dry, T. Shingles, L.J. Boshoff, G.J. Ousthuizen, J. Catalysis 15, 190 (1969).

[6] P. Soukiassian, T. Kendelewicz, in: Metallization and Metal/Semiconductor Interfaces, Ed. I.P. Batra, NATO Advance Study Insitute series, Plenum, New York, 195, 465 (1989) and references therein.

[7] H.J. Drouhin, J.C. Hermann, G. Lampel, Phys. Rev. B 31, 3859 (1985); ibid. 3872 (1985); C.Y. Su, W.E. Spicer, I. Lindau, J. Appl. Phys. 56, 1413 (1983).

[8] J.R. Hiskes, P.J. Schneider, Phys. Rev. B 23, 949 (1980); K.N. Leung, K.W. Ehlers, Rev. Sci. Instr. 55, 803 (1982).

[9] P. Soukiassian, H.I. Starnberg, in: Physics and Chemistry of Alkali Metals Adsorption, Eds. H.P. Bonzel, A.M. Bradshaw, G. Ertl, Elsevier Science Publishers B.V., Amsterdam, Materials Science Monographs 57, 449 (1989) and references therein.

[10] P. Soukiassian, M.H. Bakshi, H.I. Starnberg, Z. Hurych, T.M. Gentle, K.P. Schuette, Phys. Rev. Lett. 59, 1488 (1987).

[11] N.D. Lang, Phys. Rev. B 4, 4234 (1971); J.D. Levine, E.P. Gyftopoulos, Surf. Sci. 1, 171 (1964).

[12] A.J. Bennet, L.M. Falicov, Phys. Rev. 151, 512 (1966); J.W. Gadzuk, Surf. Sci. 6, 133 (1967); J.P. Muscat, D.M. Newns, ibid. 76, 355 (1977) and references therein.

[13] P. Soukiassian, R. Riwan, Y. Borenztein, Solid State Commun. 44, 1375 (1982).

[14] P. Soukiassian, R. Riwan, C. Guillot, J. Lecante, Y. Borenztein, Phys. Scr. Vol T 4, 110 (1983).

[15] E. Wimmer, A.J. Freeman, J.R. Hiskes, A.M. Karo, Phys. Rev. B 28, 3074 (1983); S.R. Chubb, E. Wimmer, A.J. Freeman, J.R. Hiskes, A.M. Karo, Phys. Rev. B 36, 4112 (1986).

[16] Ruqian Wu, Kailai Chen, Dingsheng Wang, Ning Wang, Phys. Rev. B 38, 3180 (1988).

[17] P. Soukiassian, R. Riwan, J. Lecante, E. Wimmer, S.R. Chubb, A.J. Freeman, Phys. Rev. B 31, 4911 (1985).

[18] D.M. Riffe, G.K. Wertheim, P.H. Citrin, Phys. Rev. Lett. 64, 571 (1990).

[19] G.M. Lamble, R.S. Brooks, D.A. King, D. Norman, Phys. Rev. Lett. 61, 1112 (1988).

[20] K. Horn, A. Hohlfeld, J. Somers, Th. Lindner, P. Hollins, A.M. Bradshaw, Phys. Rev. Lett. 63, 2488 (1988).

[21] S.A. Lindgren, L. Walldén, Solid State Commun. 25, 13 (1978); Phys. Rev. B 22, 5967 (1980).

[22] S.L. Weng, T. Gustafsson, E.W. Plummer, Phys. Rev. Lett. 39, 829 (1977); S.L. Weng, E.W. Plummer, T. Gustafsson, Phys. Rev. B 18, 1718 (1978); R.A. Bartynski, T. Gustafsson, Phys. Rev. B 35, 939 (1987); W. Drube, D. Straub, F.J. Himpsel, P. Soukiassian, C.L. Fu, A.J. Freeman, Phys. Rev. B 34, 8989 (1986).

[23] F.R. McFeely, J.F. Morar, N.D. Shinn, G. Landgren, F.J. Himpsel, Phys. Rev. 30, 764 (1984).

[24] A. Franciosi, J.H. Weaver, D.T. Peterson, Phys. Rev. B 31, 3606 (1985).

[25] S. Ciraci, I.P. Batra, Phys. Rev. Lett. 58, 877 (1986); ibid. 60, 1982 (1987); Phys. Rev. B 38, 8432 (1988).

[26] P. Soukiassian, M.H. Bakshi, Z. Hurych, T.M. Gentle, Surf. Sci. Lett. 221, L 759 (1989). 
[27] A. Franciosi, P. Soukiassian, P. Philip, S. Chang, A. Wall, A. Raisanen, N. Troullier, Phys. Rev. B 35, 910 (1987).

[28] P. Soukiassian, T. Kendelewicz, Z. Hurych, Phys. Rev. B 40, 12570 (1989).

[29] P. Soukiassian, Surf. Sci. Lett. 172, L507 (1986).

[30] P. Soukiassian, T.M. Gentle, M.H. Bakshi, A.S. Bommannavar, Z. Hurych, Phys. Scr. 35, 757 (1987).

[31] H. Tochihara, K. Kubota, Y. Murata, Solid State Commun. 57, 437 (1986).

[32] T. Aruga, H. Tochihara, Y. Murata, Phys. Rev. Lett. 53, 372 (1984).

[33] H. Ishida, N. Shima, M. Tsukada, Phys. Rev. B 32, 6236 (1985); Surf. Sci. 158, 438 (1985).

[34] P. Soukiassian, T.M. Gentle, M.H. Bakshi, Z. Hurych, J. Appl. Phys. 60, 4339 (1986).

[35] P. Soukiassian, M.H. Bakshi, Z. Hurych, T.M. Gentle, Phys. Rev. B 35, 4176 (1987).

[36] E.M. Oellig, E.G. Michel, M.C. Ascensio, R. Miranda, Appl. Phys. Lett. 50, 1660 (1987).

[37] P. Soukiassian, H.I. Starnberg, T. Kendelewicz, Appl. Surf. Sci. 41/42, 395 (1989).

[38] J.L. Desplat, C. Papageorgopoulos, Surf. Sci. 92, 97 (1980).

[39] T. Kendelewicz, P. Soukiassian, R.S. List, J.C. Woicik, P. Pianetta, I. Lindau, W.E. Spicer, Phys. Rev. B 37, 7115 (1988).

[40] S.T. Kim, P. Soukiassian, L. Barbier, S. Kapoor, Z. Hurych, Phys. Rev. B 44, 5622 (1991).

[41] Ye Ling, A.J. Freeman, B. Delley, Phys. Rev. B 39, 10144 (1989).

[42] H. Ishida, K. Terakura, Phys. Rev. B 39, 11519 (1989).

[43] S.P. Tang, A.J. Freeman, private communication.

[44] C.M. Wei, H. Huang, S.Y. Tong, G.S. Glander, M.B. Webb, Phys. Rev. B 42, 11284 (1990).

[45] Y. Ma, J.E. Rowe, E.E. Chaban, C.T. Chen, R.L. Headrick, G.M. Meigs, S. Modesti, F. Sette, Phys. Rev. Lelt. 65, 2173 (1990).

[46] Y. Enta, T. Kinoshita, S. Suzuki, S. Kono, Phys. Rev. B 36, 9801 (1987).

[47] T.E. Ortega, E.M. Oellig, J. Ferron, R. Miranda, Phys. Rev. B 36, 6213 (1987).

[48] G.S. Glander, M.B. Webb, Surf. Sci. 222, 64 (1989).

[49] M. Tikhov, G. Rangelov, L. Surnev, Surf. Sci. 231, 280 (1990).

[50] A. Hiraki, Surf. Sci. Rep. 3 No 7 (1983); K. Okuno, T. Ito, M. Iwami, A. Hiraki, Solid State Commun. 34, 493 (1980); A. Cros, J. Derrien, F. Salvan, Surf. Sci. 110, 471 (1981); A. Katnani, P. Perfetti, T.X. Zhao, G. Margaritondo, Appl. Phys. Lett. 40, 619 (1982); I. Abbati, G. Rossi, L. Calliari, L. Braicovich, I. Lindau, W.E. Spicer, J. Vac. Sci. Technol. 21, 409 (1982); A. Cros, J. Phys. (Paris) 44, 707 (1983); F.U. Hillebrecht, M. Ronay, D. Rieger, F.J. Himpsel, Phys. Rev. B 34, 5377 (1986); W.A. Henle, M.G. Ramsey, F.P. Netzer, R. Cimino, W. Braun, S. Witzel, Phys. Rev. B 42, 11073 (1990).

[51] S. Nishigaki, S. Matsuda, T. Sasaki, N. Kawanishi, H. Takeda, A. Kawase, Vacuum 41, 632 (1990).

[52] J. Levine, Surf. Sci. 34, 90 (1973).

[53] H. Tochihara, Surf. Sci. 126, 523 (1983). 
[54] S. Kohmoto, S. Mizuno, A. Ichimiya, Appl. Surf. Sci. 41/42, 107 (1989).

[55] C.M. Wei, H. Huang, S.Y. Tong, G.S. Glander, M.B. Webb, Phys. Rev. B 42, 11284 (1990).

[56] T. Urano, Y. Uchida, S. Hongo, T. Kanaji, Surf. Sci. 242, 39 (1991).

[57] T. Abukawa, S. Kono, Phys. Rev. B 37, 9097 (1988); Surf. Sci. 214, 141 (1989).

[58] S. Tanaka, N. Takagi, N. Minami, M. Nishijima, Phys. Rev. B 42, 1868 (1990).

[59] T. Makita, S. Kohmoto, A. Ichimiya, Surf. Sci. 242, 65 (1991).

[60] A.J. Smith, W.R. Graham, E.W. Plummer, Surf. Sci. Lett. 243, L 37 (1991).

[61] P. Soukiassian, J.A. Kubby, in: Structure of Surfaces - III, Springer series in Surface Science, Eds. S.Y. Tong, M.A. Van Hove, K. Tagayanki, Xie Xide, Springer-Verlag, Berlim, Vol. 24, 584 (1991).

[62] J.A. Kubby, W.J. Greene, P. Soukiassian, J. Vac. Sci. Technol. B 9, 739 (1991).

[63] S. Kennou, M. Karamatos, S. Ladas, C. Papageorgopoulos, Surf. Sci. 216, 462 (1989).

[64] R. Riwan, P. Soukiassian, S. Zuber, J. Cousty, Surf. Sci. 146, 382 (1984).

[65] K.M. Choudhary, P.S. Mangat, H.I. Starnberg, Z. Hurych, D. Kilday, P. Soukiassian, Phys. Rev. B 39, 759 (1989).

[66] H.I. Starnberg, P. Soukiassian, Z. Hurych, Phys. Rev. B 39, 12775 (1989); H.I. Starnberg, P. Soukiassian, M.H. Bakshi, Z. Hurych, Surf. Sci. 224, 13 (1989) and references therein. 